\title{
Study on Light Transmitting Through Cement Mortar Brick
}

\author{
P.Jagannadharao ${ }^{1}$ N.V.L.Npavankumar ${ }^{2}$ V.Udaya Bhanu ${ }^{3}$
}

\begin{abstract}
Natural light in buildings is obstructed by the development of high-rise buildings. To overcome this problem, the use of artificial light increases large amounts. And power consumptions will be more. This becomes necessary to decrease the amount of artificial light by introducing Light Transmission Concrete named as LiTraCon. From the steel industries more quantity of slag come out and disposal of that require a large quantity of land, water and energy and its fine particles of not disposed of properly by virtue of their weightless can become airborne and affect the environment. This slag consistent with some same similar properties like Cement \& Sand, because of this reason the cement/Sand can be replaced with slag to reduce the cost of transparent. The slag enhances the use of the waste product and makes concrete environment-friendly. In this experiment, we are going to deal with the comparison of a few parameters like strength, density, economical and its applications.
\end{abstract}

Key words: Natural Light, Transmitting, Sustainability, Blast Furnace Slag, Optical Fiber, Translucent.

\section{INTRODUCTION:}

The major issues are in society are economic development and space utilization requirements, high rise buildings and skyscrapers are mostly built in major cities around the world, especially countries with more populations. This arises one of the problems in deriving natural light in the building, due to obstruction of nearby structures. So, it is very essential to reduce artificial like consumption in structure.

It is considered to be one of the best sensor materials available and has been wide since the 1990s. Hungarian architect, Aron Losonczi, first introduce the idea of light-transmitting concrete in 2001 and then successfully produced the first transparent concrete block in 2003, named LiTraCon. However, this lighttransmitting concrete did not have smart sensing properties. Light transmitting concrete is also known as transparent concrete is a novel construction material manufactured with optical fiber by drilling through the cement and mortar in order to utilize the light-guiding ability of the optical fiber. This research helps to use natural light as a major resource in order to decrease power consumption.

Light transmitting concrete are available as prefabricated blocks/panels. LiTraCon rooms will be brightened and proximal objects situated on the brighter side of the transparent wall will be revealed as silhouettes on the other side. The researchers told that only $4 \%$ of optical fibers usage in concrete helps more, and some amount of light is transmitted because of their parallel arrangement in a matrix between the two outer surfaces of each block. The load-bearing structure can also be built from these blocks since optical fibers have no negative effect on the strength of the concrete.

\section{PRINCIPLE OF LIGHT TRANSMISSION/TRANSMITTING}

Transparent concrete or translucent concrete in work based on Nano-Optics". Optical fibers pass as much light when tiny slits or place directly on top of each other as when they are staggered. It is because of optical fibers in the concrete act as slits and traveling the light throughout the concrete.

Thousands of optical glass fibers from a matrix and run parallel to each other between two main surfaces of each block. The fibers mingle in the concrete because of their significant size and they become a structural component as a kind of modest aggregate.

In this research, we can use only fine concrete with optical fibers for light transmitting through concrete. It can be produced as prefabricated building blocks and panels. Due to the small size of fibers, they blend into concrete becoming the component of material like small pieces of aggregate. By arranging high numerical aperture plastic optical fibers (POF) or big diameter glass optical fiber into concrete, it transmits light so effectively that there is virtually no loss of light conducted through the fibers.

Placing of parallel position, the light-transmission on the outside of a wall appears on the darker side the most interesting form of this phenomenon is probably shadows on the opposing side of the wall. Moreover, the color of the light also remains the same. 


\section{OPTICAL FIBER}

Optical fiber is the technology associated with data transmission using light pulses traveling along with a long fiber which is usually made of plastic or glass. Metal wires are preferred for transmission in optical fiber communication as signals travel with fewer damages. Optical fibers are also unaffected by electromagnetic interference. The optical fiber uses the application of total internal reflection of light. The fibers are designed to facilitate the transmission of light along the optical fiber depending on the requirement of power and distance of transmission. Single-Mode fiber is used for long-distance transmission while multimode fiber is used for shorter distances. The outer cladding of these fibers needs better protection than metal wires.

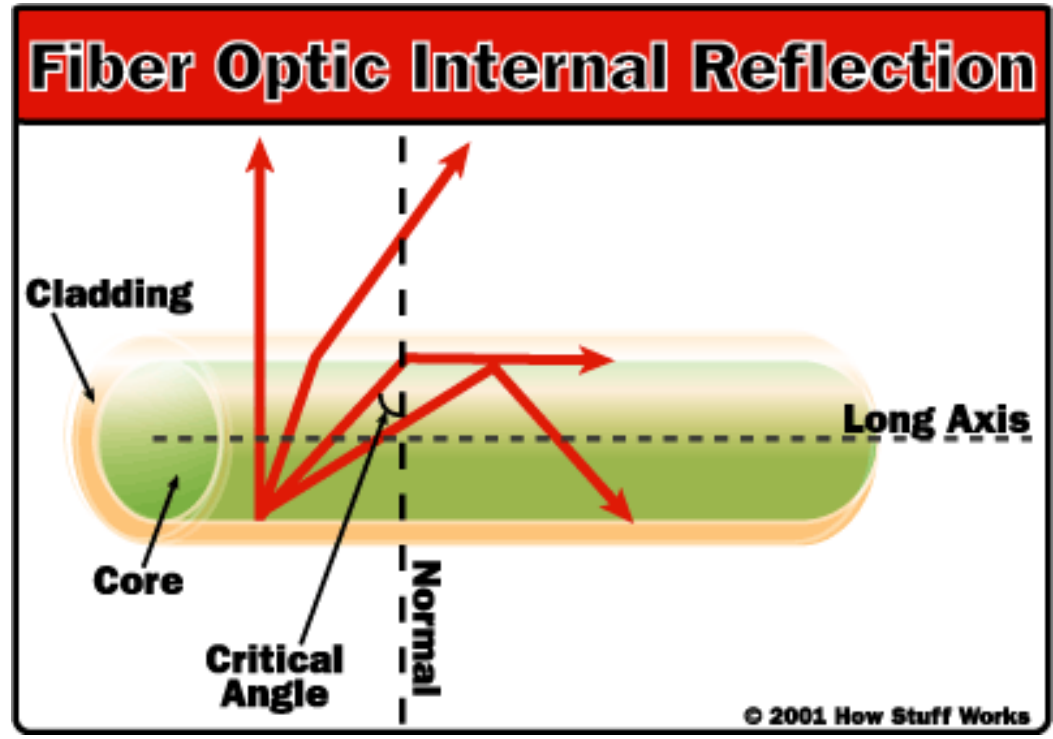

Source: https://computer.howstuffworks.com/fiber-optic6.htm

\subsection{Total internal reflection:}

When light travelling in an optically dense medium hits a boundary at a steep angle (larger than the critical angle for the boundary). The light is completely reflected. This is called total internal reflection. The process of total internal reflection is shown in Fig. The effect is used in optical fiber to confine light in the core. Light travels through the fiber core, bouncing back and forth of the boundary between the core and cladding. Because the light must strike the boundary with an angle greater than critical angle, only light that enters the fiber with in a certain range of angles can travel down the fiber without leaking out. This range of angles is called acceptance cone of fiber. The size of the acceptance cone is a function of the reflective index difference between the fibers core and cladding.

\subsection{Advantages of Optical Fibres:}

Optical fibres are used in a large number fields in modern times, ranging from minor electrical instruments in computers to remote sensing. Developed in the 1970s, these were initially intended for communication purposes (telecommunications industry). Do not produce radiation and are completely immune to radio magnetic interference and radio frequency interference and noise. By far, this is the best replacement for glass, being much stronger, and giving more privacy. Plastic optical fibres are the ones used in this research. There are a few types of optical fibres, each with a certain property like metal free, high fibre count, etc. They have certain advantages over other materials like glass. More pliable: POF (plastic optical fibres) possesses this ability to bend in different shapes. Their bending radius is very less. They are more resilient to damage and abuse than glass due to its intrinsic material characteristics Cutting, wiring, bonding, connecting and other processes are easier.

\subsection{Blast Furnace Slag:}

Blast furnace (BF) slag is a nonmetallic by product produced during the process of iron making in a blast furnace. It consists primarily of silicates, aluminosilicates, and calcium-alumina-silicates. The molten slag usually absorbs most of the sulfur from the blast furnace charge. 


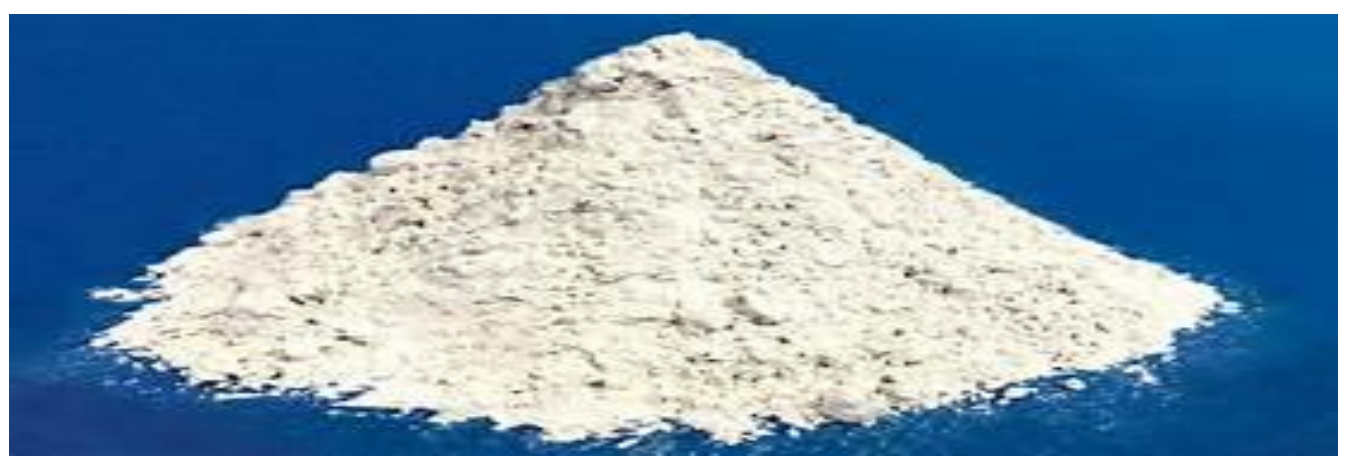

\section{SCOPE OF THE PROJECT}

Translucent concrete is also a great insulating material that protects against outdoor extreme temperatures while also letting in daylight. This makes it an excellent compromise for buildings in harsh climates, where it can shut out heat or cold without shutting the building off from daylight. It can be used to illuminate underground buildings and structures, such as subway stations. The possibilities for translucent concrete are innumerable; the more it is used; the newer uses will be discovered. In the next few years, as engineers further explore this exciting new material, it is sure to be employed in a variety of interesting ways that will change the opacity of architecture as we know it.

\section{FINE AGGREGATE}

Aggregate whose particle size varies from $0.075 \mathrm{~mm}$ to $4.75 \mathrm{~mm}$ are called as fine aggregates. Generally, the fine aggregates consist of natural sand or crushed stone with more particles passing through a sieve.

\begin{tabular}{|c|c|c|c|}
\hline S.No & Property & $\begin{array}{c}\text { Require-mentas per IS } \\
\mathbf{3 8 3 - 1 9 7 0}\end{array}$ & Blast furnace slag \\
\hline 1. & Specific Gravity & 2.6 & 2.4 \\
\hline 2. & Fineness modulus & $3.48($ Zone-1) & 3.8 \\
\hline 3. & Water Absorption & 0.30 & 0.40 \\
\hline 4. & Bulk Density $(\mathrm{kg} / \mathrm{m} 3)$ & 1586 & 1610 \\
\hline
\end{tabular}

The property of blast furnace slag should be tested whether this material has same similar properties as like fine aggregate and also should know whether it has holding property or not.

\subsection{FINE AGGREGATE}

Tests on Fine Aggregate

$\odot \quad$ 1. Specific gravity

$\odot \quad$ 2. Fineness

$\odot \quad$ Bulking of Sand

\subsection{Blast Furnace SLAG:}

$\begin{array}{ll} & \text { Tests on slag } \\ \odot & \text { 1. Specific gravity } \\ \odot & \text { 2. Fineness } \\ \odot & \text { Bulking of Slag }\end{array}$

Result

3.10

$4.2 \%$

$15.5 \%$

Result

2.81

5.32

$18 \%$
Range between

3.10 to 3.15

less than $10 \%$

Less than $30 \%$ 


\section{EXPERIMENTAL PROCEDURE}

Step 1-Preparation of the Mould:

Step 2- Optical Fibre:

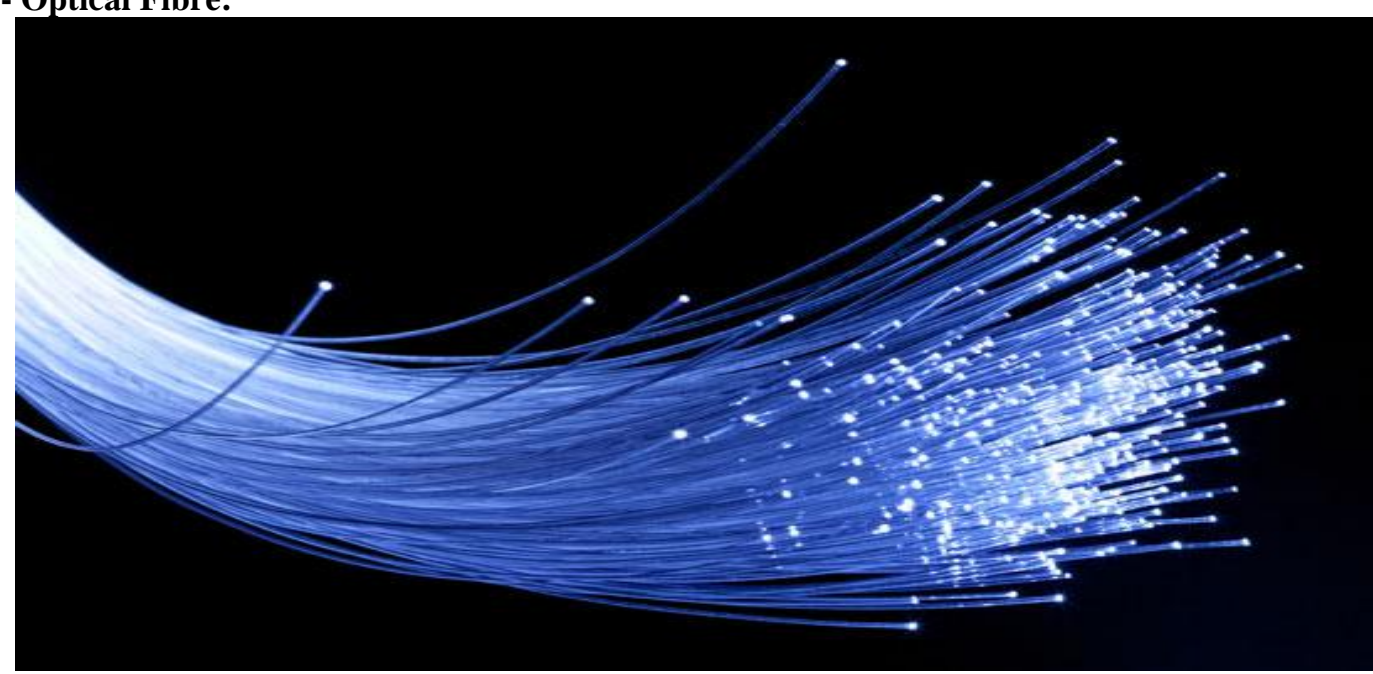

Source: https://cdn.britannica.com/84/91884-004-DDDE5A86.jpg

Step 3- Fixing the Fibres:

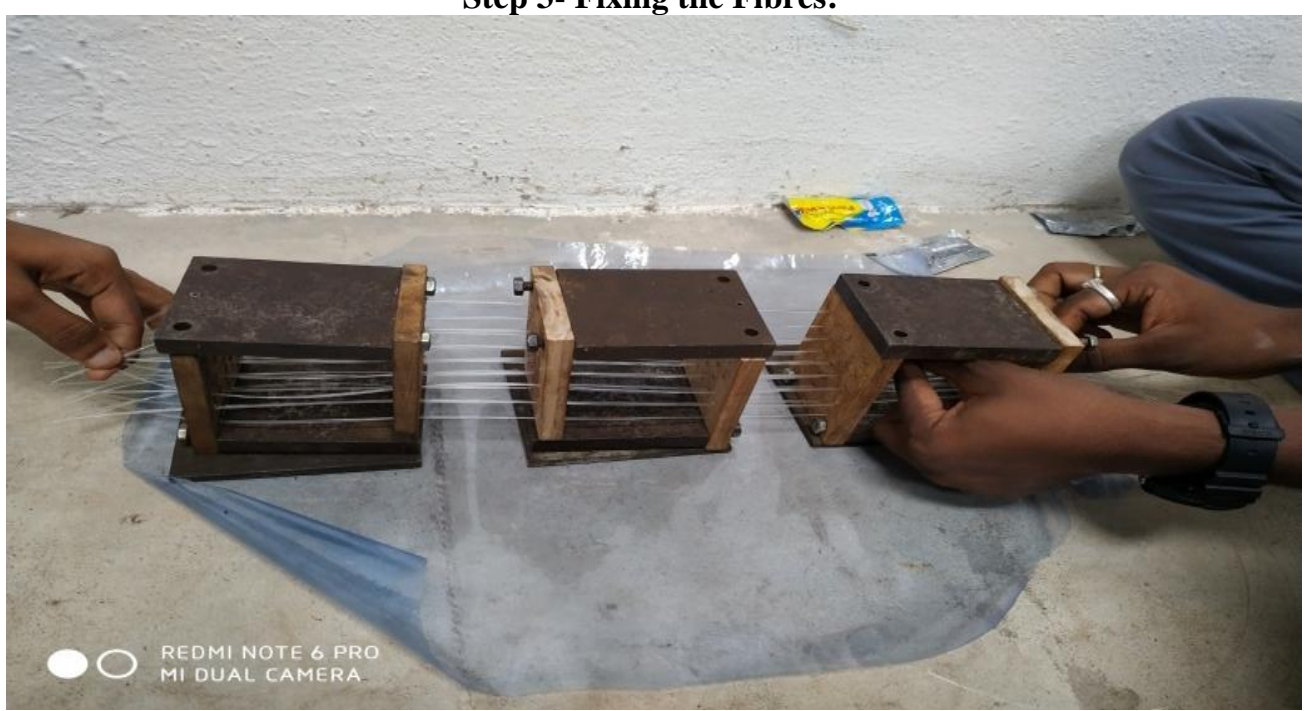

Step 4- Casting the Specimen:

Step 5: Cutting of Excess Optical fibres:

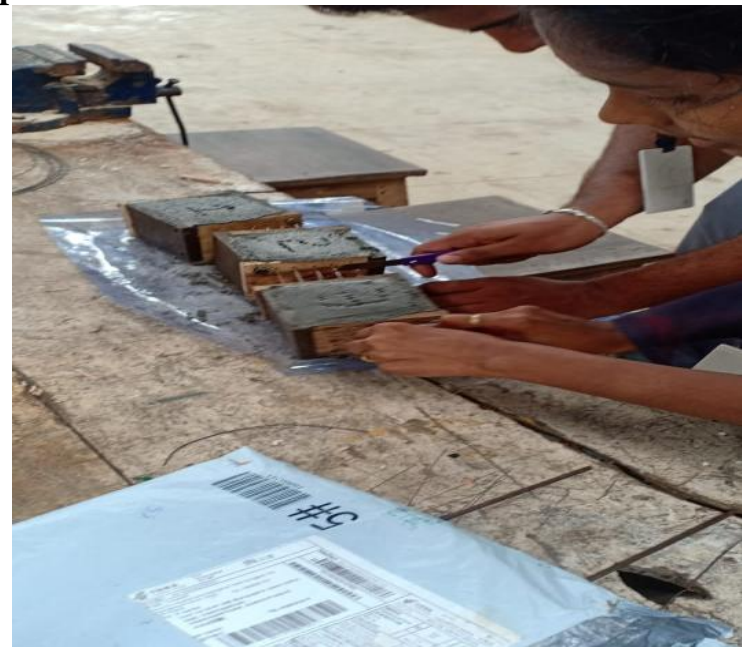


7 Preparation of mould (Prototype Model with plywood) (Size of the mould 30*11*10 cm)

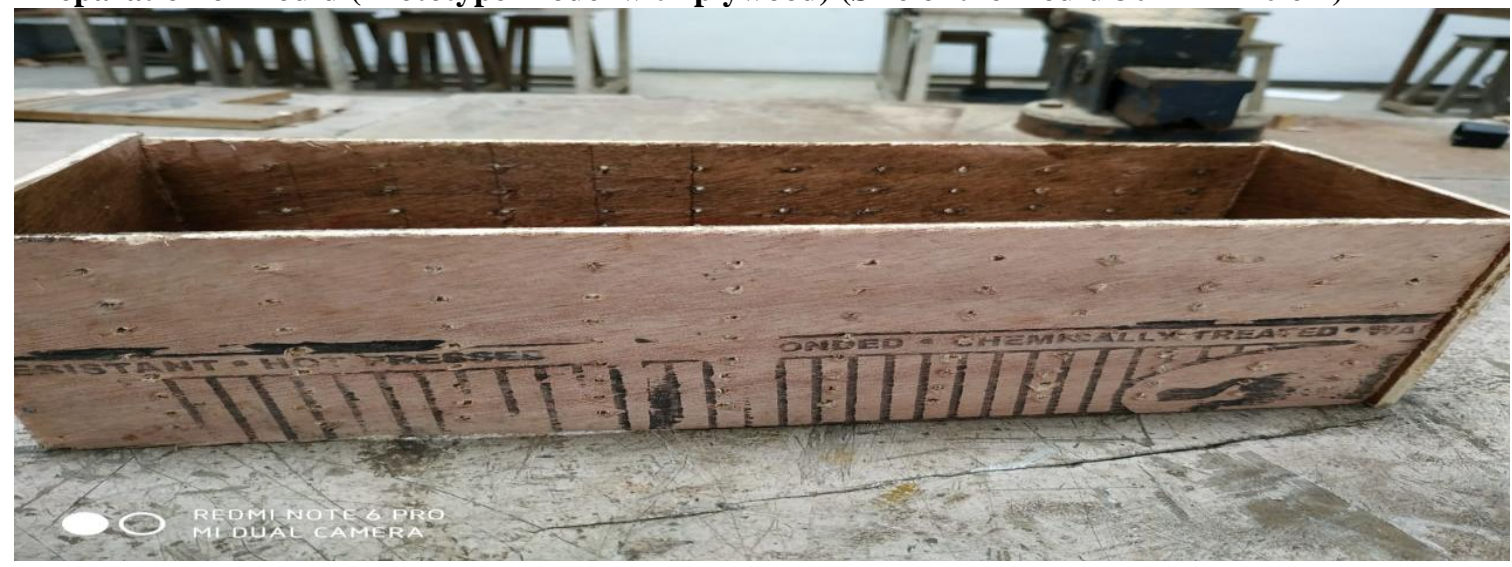

Preparation of Prototype model

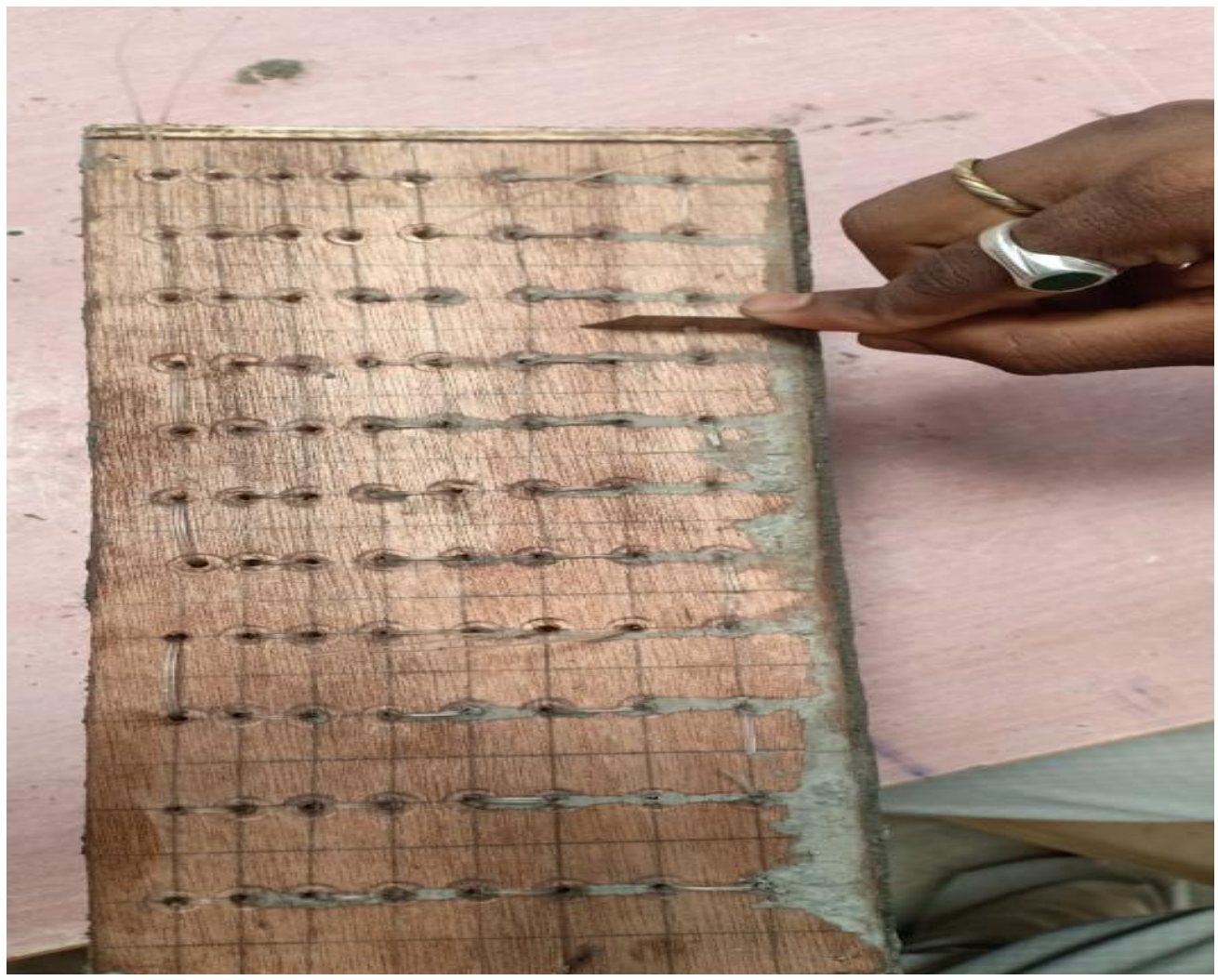

Inserting of optical Fibres into Prototype Model followed by Casting and Furnishing the Specimen 


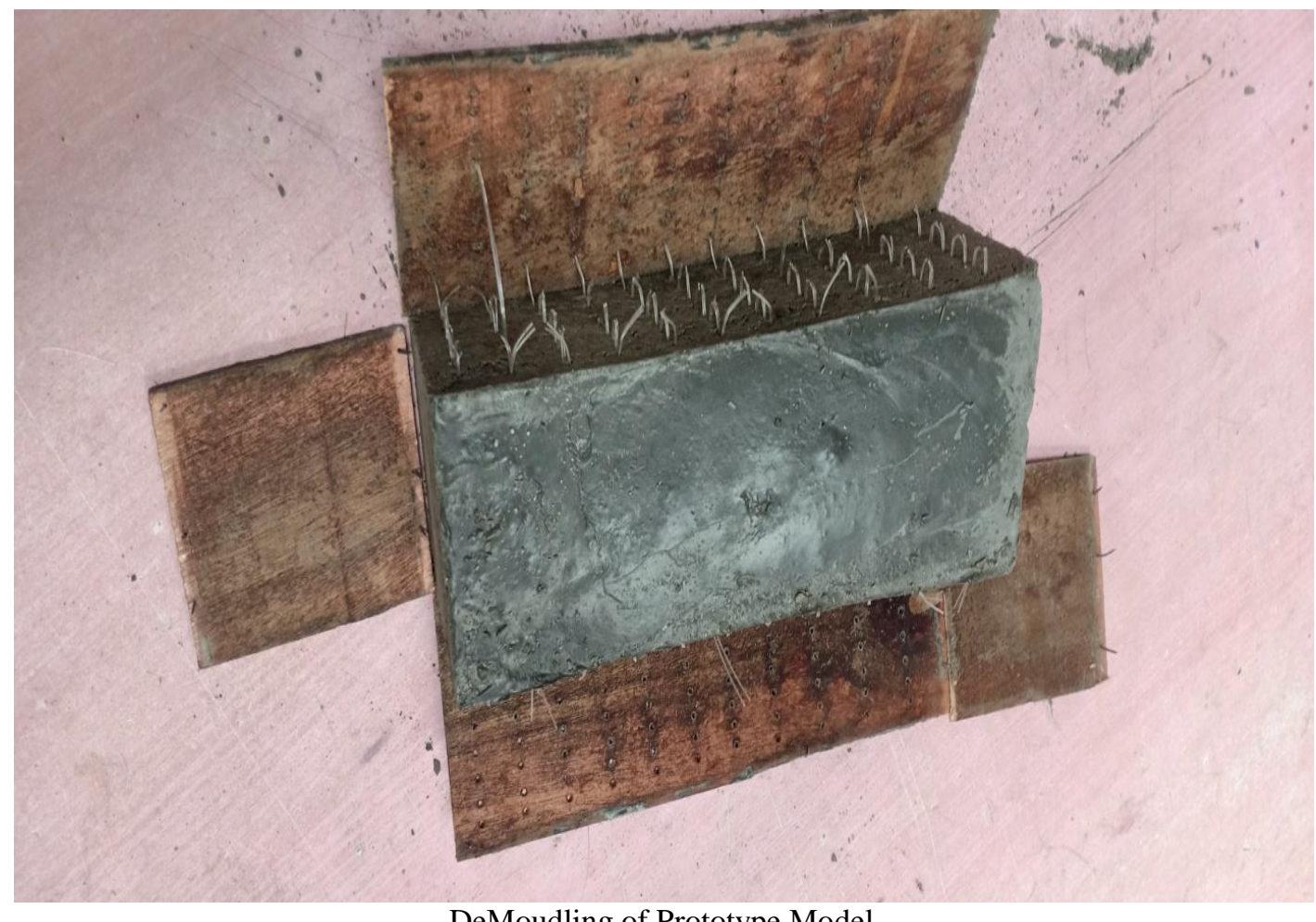

DeMoudling of Prototype Model

VII. RESULTS AND DISCUSSION

Results of Conventional Mortar Mix 1:3:

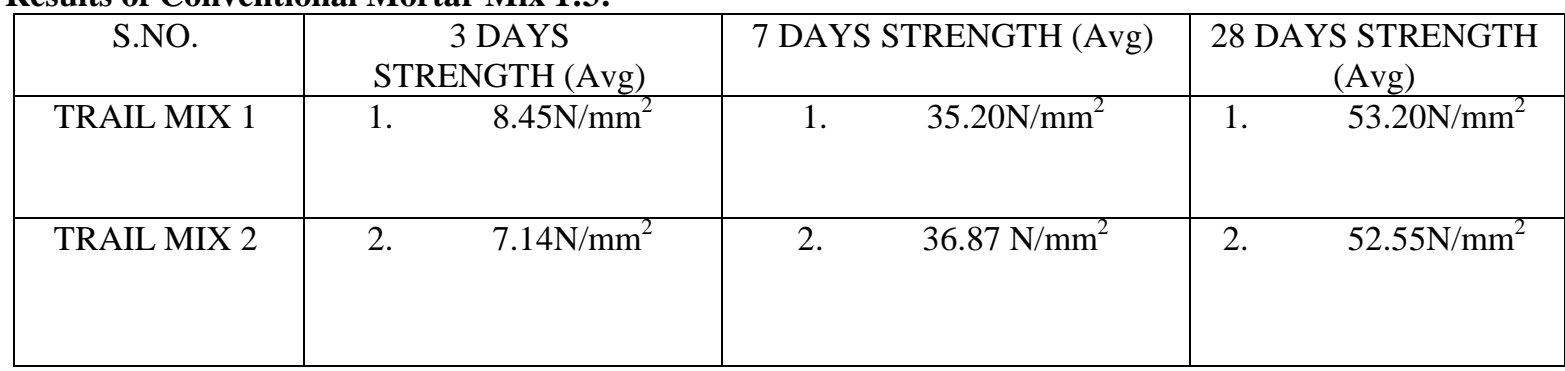

Results of Mortar Mix with $50 \%$ of Sand replacement with BFS:

\begin{tabular}{|c|c|c|c|}
\hline S.NO. & $\begin{array}{c}3 \text { DAYS } \\
\text { STRENGTH }\end{array}$ & 7 DAYS STRENGTH & 28 DAYS STRENGTH \\
\hline TRAIL MIX 1 & $7.42 \mathrm{~N} / \mathrm{mm}^{2}$ & $36.04 \mathrm{~N} / \mathrm{mm}^{2}$ & $51.94 \mathrm{~N} / \mathrm{mm}^{2}$ \\
\hline TRAIL MIX 2 & $7.95 \mathrm{~N} / \mathrm{mm}^{2}$ & 2. $\quad 34.98 \mathrm{~N} / \mathrm{mm}^{2}$ & $50.88 \mathrm{~N} / \mathrm{mm}^{2}$ \\
\hline
\end{tabular}

Results of Mortar Mix with $100 \%$ of Sand replacement with BFS:

\begin{tabular}{|l|rc|lc|lc|}
\hline \multicolumn{1}{|c|}{ S.NO. } & \multicolumn{2}{|c|}{$\begin{array}{c}\text { 3 DAYS } \\
\text { STRENGTH }\end{array}$} & \multicolumn{2}{c|}{7 DAYS STRENGTH } & 28 DAYS STRENGTH \\
\hline $\begin{array}{l}\text { TRAIL MIX 1 } \\
(1: 3)\end{array}$ & 1. & $5.36 \mathrm{~N} / \mathrm{mm}^{2}$ & 1. & $30.74 \mathrm{~N} / \mathrm{mm}^{2}$ & 1. & $42.67 \mathrm{~N} / \mathrm{mm}^{2}$ \\
\hline $\begin{array}{l}\text { TRAIL MIX 2 } \\
(1: 3)\end{array}$ & 2. & $5.19 \mathrm{~N} / \mathrm{mm}^{2}$ & 2. & $28.09 \mathrm{~N} / \mathrm{mm}^{2}$ & 2. & $42.14 \mathrm{~N} / \mathrm{mm}^{2}$ \\
\hline
\end{tabular}

Comparison of Results with \& without replacement of BFS: 
Study on Light Transmitting Through Cement Mortar Brick

\begin{tabular}{|l|c|c|c|c|}
\hline \multicolumn{1}{|c|}{ S.NO. } & Mix & $\begin{array}{c}\text { 3 Days } \\
\text { Strength }\end{array}$ & 7 Days Strength & 28 Days Strength \\
\hline AVG TRAIL MIX (Conventional) & $1: 3$ & $7.86 \mathrm{~N} / \mathrm{mm}^{2}$ & $36.29 \mathrm{~N} / \mathrm{mm}^{2}$ & $52.28 \mathrm{~N} / \mathrm{mm}^{2}$ \\
\hline $\begin{array}{l}\text { AVG TRAIL MIX (Replaced with 50\% } \\
\text { BFS) }\end{array}$ & $1: 3$ & $7.59 \mathrm{~N} / \mathrm{mm}^{2}$ & $3 . .18 \mathrm{~N} / \mathrm{mm}^{2}$ & $49.91 \mathrm{~N} / \mathrm{mm}^{2}$ \\
\hline $\begin{array}{l}\text { AVG TRAIL MIX (Replaced with 100\% } \\
\text { BFS) }\end{array}$ & $1: 3$ & $5.07 \mathrm{~N} / \mathrm{mm}^{2}$ & $27.71 \mathrm{~N} / \mathrm{mm}^{2}$ & $42.62 \mathrm{~N} / \mathrm{mm}^{2}$ \\
\hline
\end{tabular}

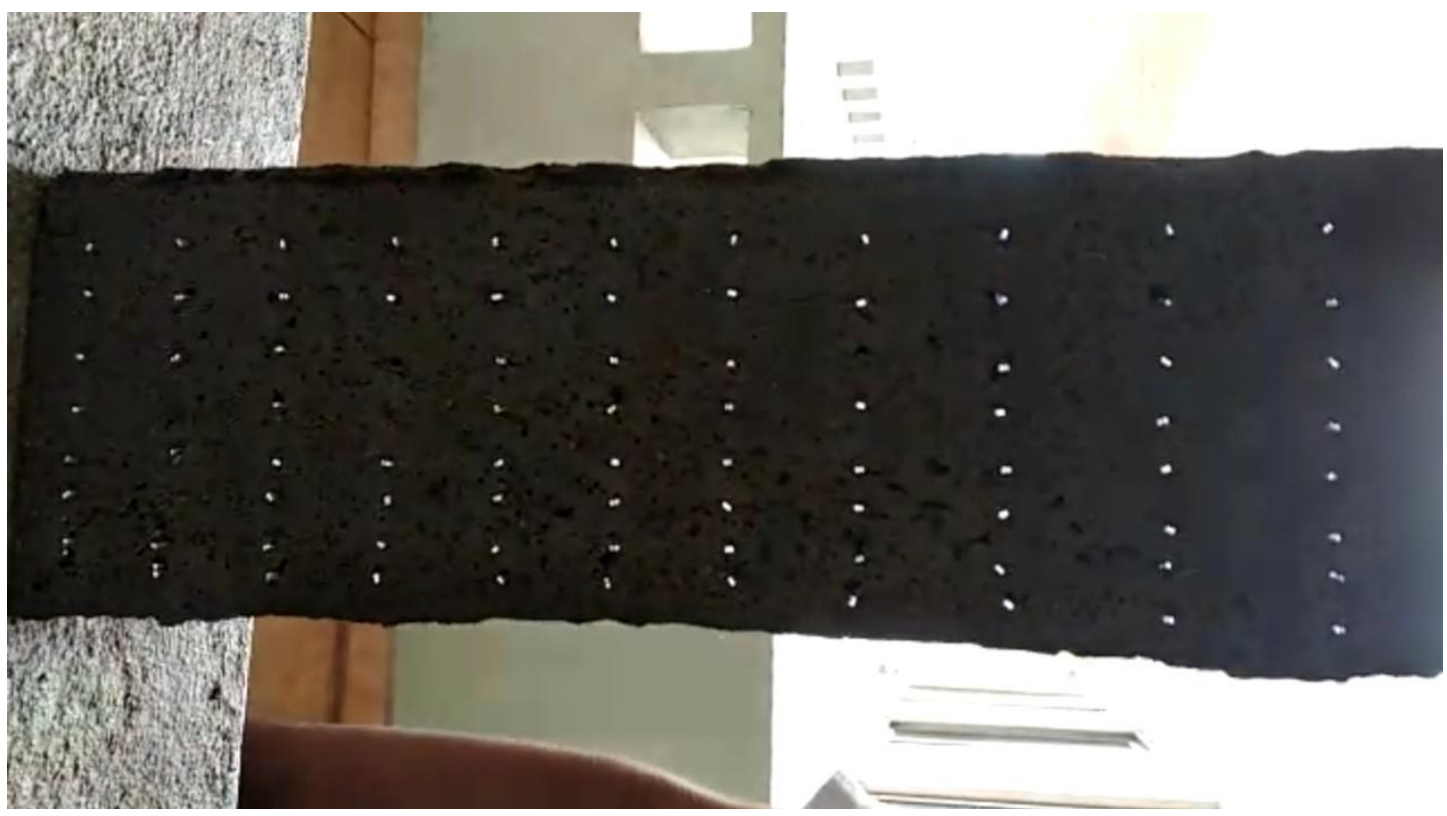

Light Transmitting Through Mortar Brick (Prototype Model)

\section{Recommendations/Applications:}

1. We are recommending this type of Optical Fibres, where we are trying to reduce power consumption

2. And also recommended at where we are facing difficulty of entering natural light at Day time.

3. At industrial areas, Laboratories

4. Partition walls

5. At roofs (where live/imposed loads are not obtain)

6. Gable walls at Huge Poultry's

7. Floors at single storey buildings (increasing the diameter of Optical Fibres)

8. We can use this Type of granular where Less availability of Sand.

\section{CONCLUSION}

1. Letting natural light-in through concrete component is a simplest way to reduce the power consumption.

2. Availability of Optical fibres more. And cost is little bit more.

3. Phenomenon of Light Transmitting through concrete body is very economical for small structures.

4. To reduce the power consumption by using this type of mix design at wall construction instead of making brick type walls.

5. Compare to brick masonry wall, wall of mortar mix with optical fibres are high but the overall performance was good.

6. Getting good results at using Blast Furness Slag instead of Natural sand.

7. Increasing the usage of Waste Materials (Locally available)in construction instead of decreasing our Natural Resources now becoming trendy.

8. With $50 \%$ of BFS replacing instead of natural sand getting satisfactory results

9. With $100 \%$ of BFS replacing instead of natural sand getting dissatisfaction results.

10. Now we recommended, using of 50\% BFS instead of natural sand i.e., Fine Aggregate.

\section{REFERENCES}

[1]. Light Transmitting Concrete by using Optical Fibre by A. B. Sawant, R. V. Jugdar, S. G. Sawant International Journal of Inventive Engineering and Sciences (IJIES) ISSN: 2319-9598, Volume-3 Issue-1, December 2014

[2]. Experimental Study of Light Transmitting Concrete Using Optical Fibre by mlan Kumar Sahoo, Sachin Sahu, Aman Kumar Singhal, KuramanaStephen, Tamo Talom, Subham Saroj Tripathy, Sidhant Das 
[3]. Smart Light Translucent Concrete ByUsing Optical Fibre by Urmila M Bhanuse, Abhijeet B BabarandAnil C Ranveer ECET; December 2015February 2016; Sec. C; Vol.5.No.1, 010-018E-ISSN: 2278-179X

[4]. Experimental Study on Light Transmitting Concrete by Awadhesh Kumar ${ }^{1}$, Rahul Ahlawat ${ }^{2}$ IJISET - International Journal of Innovative Science, Engineering \& Technology, Vol. 4 Issue 6, June 2017 ISSN (Online) 2348 - 7968 | Impact Factor (2016) 5.264

[5]. Effect of Fiber Pattern in Strength of Light Transmitting Concrete by Dinesh Babu K, Mercy Shanthi R, Suji D International Journal of Recent Technology and Engineering (IJRTE) ISSN: 2277-3878, Volume-7, Issue-5S4, February 2019

[6]. Study on Light Transmittance of Concrete Using Optical Fibers and Glass Rods. Prof. A.A. Momin1 , Dr. R.B. Kadiranaikar2 , Mr.Vakeel.S. Jagirdar1 , Mr. Arshad Ahemed Inamdar1 IOSR Journal of Mechanical and Civil Engineering (IOSR-JMCE) e-ISSN 2278-1684, p-ISSN: 2320-334X PP 67-72

[7]. STUDY ON MECHANICAL PROPERTIES OF LIGHT TRANSMITTING CONCRETE by B.YAMINI NIRMAL1, Mr. K.NEHEMIYA2, Sri .G.GIRI PRASAD3, International Research Journal of Engineering and Technology (IRJET) e-ISSN: 23950056 Volume: 04 Issue: 07 | July -2017 www.irjet.net p-ISSN: 2395-0072

[8]. AN EXPERIMENTAL STUDY ON LIGHT TRANSMITTING CONCRETE by International Research Journal of Engineering and Technology (IRJET) e-ISSN: 2395-0056 Volume: 06 Issue: 05 | May 2019 www.irjet.net p-ISSN: 2395-0072

[9]. EXPERIMENTAL STUDY ON LIGHT TRANSMITTING CONCRETE BY USING OPTICAL FIBRE, S.Suganya* \& S.Minu Gopika International Journal of Engineering Research and Modern Education Impact Factor 6.525, Special Issue, April - 2017

[10]. https://www.slideshare.net/SahlaFathima/light-transmitting-concrete

P.Jagannadharao, et. al. "Study on Light Transmitting Through Cement Mortar Brick." International Journal of Engineering Science Invention (IJESI), Vol. 09(05), 2020, PP 05-12. 